\title{
A responsabilização da família na cena contemporânea: particularizando - Programa Criança Feliz
}

Family responsibilization in the contemporary scenario: particularizing the Happy Child Program

\author{
Ana Cristina Brito Arcoverde* \\ Elisa Celina de Alcantara** \\ Josinete de Carvalho Bezerra***
}

\begin{abstract}
Resumo - O presente artigo constitui-se numa reflexão teórica em que abordamos elementos que tendem a resultar na culpabilização das famílias numa conjuntura de regressão de direitos. Enfatizam-se os retrocessos nos direitos e políticas sociais, com enfoque na intensificação de programas que caminham na contramão da política de assistência social, particularizando o Programa Criança Feliz, instituído em 2016 no Brasil. Objetiva-se, assim, identificar as especificidades do processo de desresponsabilização do Estado diante das necessidades sociais, desenvolvendo estratégias que exigem maior atuação da família no provimento da proteção social. Identifica-se uma culpabilização e responsabilização das famílias diante de sua situação de vulnerabilidade social, com ênfase maior na questão moral e não protetiva.
\end{abstract}

Palavras-chave: política de assistência social; Programa Criança Feliz; família.

\begin{abstract}
The present article deals with a theoretical reflection that aims to analyze elements that may result in the blame of the families in the conjuncture of regression of rights. In this sense, the setbacks in social rights and policies are emphasized, with a focus on intensifying programs that run counter to the social assistance policy, particularly the Happy Child Program, instituted in Brazil in 2016. Thus, the objective is to identify the specificities of the State's lack of accountability in the face of social needs, developing strategies that require a greater role for the family in
\end{abstract}

\footnotetext{
* Professora do Departamento de Serviço Social e do Programa de Pós-Graduação em Serviço Social da Universidade Federal de Pernambuco (UFPE). Assistente social, graduada em Direito, mestre em Serviço Social pela UFPE, doutora em Sociologia pela Université La Sorbonne-Nouvelle e pós-doutora em Psicologia da Educação pela UnB. Líder do grupo de pesquisa Ações em Redes Coordenadas (ARCUS). E-mail: ana.arcoverde@gmail.com. ORCID: https://orcid.org/0000-0002-8344-5533.

** Mestranda em Serviço Social pela Universidade Federal de Pernambuco (UFPE). Especialista em Gestão de Programas e Projetos Sociais. Pesquisadora do grupo de pesquisa Ações em Redes Coordenadas (ARCUS). Correspondência:. E-mail: elisacelinamelo@hotmail.com. ORCID:. https://orcid.org/0000-0002-8064-2921.

*** Mestranda em Serviço Social pela Universidade Federal de Pernambuco (UFPE). Pesquisadora do grupo de pesquisa Ações em Redes Coordenadas (ARCUS).. E-mail: josinetecarvalhobezerra@gmail.com. ORCID: https:/ /orcid.org/0000-0002-9209-8660.
} 
\} A RESPONSABILIZAÇÃO DA FAMÍLIA NA CENA - ARCOVERDE, A. C. B.; ALCANTARA, E. C.; BEZERRA, J. C. \} DOI: $10.12957 /$ REP.2019.45221

providing social protection. It identifies the blaming and accountability of families facing situations of social vulnerability with a greater emphasis on moral and non-protective issues.

Keywords: Social Assistance Policy; Happy Child Program; Family.

\section{Introdução}

O presente artigo constitui-se numa reflexão teórica. Desse modo, visa analisar elementos contraditórios que podem resultar na culpabilização das famílias na conjuntura contemporânea de regressão de direitos.

Intensificam-se os retrocessos nos direitos e nas políticas sociais, com enfoque na criação de programas que caminham na contramão da política de assistência social e que, portanto, tendem a resultar em impactos significativos. Assim, particularizamos o Programa Criança Feliz, instituído através do Decreto $n^{\circ}$ 8.869, de 5 de outubro de 2016, no Brasil (BRASIL, 2016b). O objetivo, assim, é identificar as especificidades do processo de desresponsabilização do Estado diante das necessidades sociais, desenvolvendo estratégias que exigem maior atuação da família no provimento da proteção social, como propõe o referido programa.

O trabalho está organizado em três momentos. Inicialmente, abordam-se as configurações da cena contemporânea, salientando a crise estrutural do capital e, consequentemente, as estratégias desenvolvidas pelo sistema capitalista com o intuito de manter a acumulação, ao mesmo tempo em que restringe direitos e políticas sociais. Posteriormente, ressaltam-se as novas relações estabelecidas entre a família e as políticas sociais na conjuntura de regressão de direitos. Desse modo, é analisado um contexto de culpabilização dessas famílias por meio de maior responsabilização para provimento de proteção social, uma vez que cabe aos pais e/ou responsáveis o entendimento de prover o bem-estar de seus filhos, independentemente do contexto social vivenciado.

Por fim, discutem-se as características do Programa Criança Feliz, considerado uma nova estratégia para intensificar a desresponsabilização do Estado e o próprio desmonte das políticas sociais, pois institui uma metodologia de atendimento ${ }^{1}$ pautada em princípios da política de saúde e da assistência social, porém, divergindo dos serviços socioassistenciais. $O$ referido programa constitui-se num importante mecanismo de retrocesso e desproteção social e, portanto, precisa ser estudado criticamente.

As famílias inseridas num sistema antagônico e explorador, ao enfrentarem uma conjuntura de retrocesso e regressão de direitos, intensificada após o Golpe 2016, não possuem condições de prover proteção social

${ }^{1}$ Neste caso, o método CDC - Cuidados para o Desenvolvimento da Criança. 


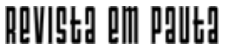

\} A RESPONSABILIZAÇÃO DA FAMÍlIA NA CENA - ARCOVERDE, A. C. B.; ALCANTARA, E. C.; BEZERRA, J. C. \}

DOI: $10.12957 /$ REP.2019.45221

sem o apoio do aparelho estatal. Assim sendo, não é subtraindo suas funções que o atendimento aos sujeitos em vulnerabilidade será viabilizado, uma vez que, enquanto prevalecer o sistema capitalista, ao Estado cabe o dever de garantir direitos e, dessa maneira, a proteção social. Entretanto, a responsabilização da família na contemporaneidade constitui-se numa estratégia que resulta em desproteção social.

\section{Crise e as novas estratégias do capital: o desmonte das políticas sociais}

O modo de produção capitalista é caracterizado por particularidades que explicitam contradições inerentes a duas classes antagônicas, os trabalhadores e os capitalistas. Assim sendo, as relações sociais são permeadas de interesses divergentes, em que o que beneficia uma classe não se configura em benefícios para outra. Essa realidade é mais perceptível ainda em momentos como o do cenário atual, de aprofundamento da crise estrutural do sistema do capital, conforme aponta Mészáros (2002).

A crise ${ }^{2}$ é inerente ao sistema capitalista, pois é imprescindível para seu desenvolvimento e constitui-se, portanto, como cíclica. Todavia, em momentos de crise este capital necessita estabelecer estratégias de enfrentamento e/ou superação da mesma, visando reestruturar seu poder dominante e mantendo a acumulação e a lucratividade. Ou seja, esses desequilíbrios podem não alterar e/ou impactar o processo de aumento de sua riqueza, de modo que podemos pensar as crises econômicas não como momentos de colapso da reprodução ampliada do capital, mas como mecanismo através do qual a lei do valor se impõe (MANDEL, 1990).

Ao desenvolver formas de reestruturar o capital, são adotadas medidas de enfrentamento em detrimento dos direitos da classe trabalhadora; dessa maneira, é imprescindível readequar o processo de produção, alterando também as relações sociais de reprodução. Nas conjunturas de crise econômica, o desenlace desse movimento torna-se mais explícito, pois a necessidade de criar mecanismos de contratendência à queda tendencial da taxa de lucro revela a estreita vinculação entre os requerimentos do processo de valorização e realização do capital e as condições sociopolíticas. Sob elas, o capital procura superar as crises de sua reprodução, sem perder a condição de classe hegemônica, valendo-se, dentre outras medidas, das políticas sociais, como bem postula Mota (2015).

Acompanha-se, então, um reordenamento das políticas sociais, no qual a função social do aparelho estatal é subtraída. Assim sendo, no contexto de recorte neoliberal, o atendimento às necessidades sociais é

\footnotetext{
${ }^{2}$ Segundo Netto (2012), crises, não só as financeiras, também fazem necessariamente parte da dinâmica capitalista: não existe capitalismo sem crise.
} 


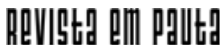

\} A RESPONSABILIZAÇÃO DA FAMÍLIA NA CENA - ARCOVERDE, A. C. B.; ALCANTARA, E. C.; BEZERRA, J. C. \}

DOI: $10.12957 /$ REP.2019.45221

destinado ao mercado, ao terceiro setor e às famílias, exigindo, portanto, maior participação da sociedade civil no provimento da proteção social.

Ao ampliarem-se no pós-golpe de 2016 os novos mecanismos de exploração da força de trabalho, de supressão de direitos sociais e especialmente de privatização e/ou mercantilização da educação, da saúde, da previdência e, consequentemente, dos serviços públicos, nos parece que a família assume lugar ainda mais estratégico no processamento desses mecanismos, especialmente em relação à privatização da provisão de bem-estar. (HORST; MIOTO, 2017, p. 228-246).

Diante de tal conjuntura, intensifica-se a demanda por um Estado que atue com políticas residuais e compensatórias. Para tanto, são desenvolvidas estratégias de restrição de acesso a bens e serviços públicos, com brutal contenção de gastos e, consequentemente, desresponsabilização do aparelho estatal.

Esta realidade resulta em sucateamento, desmonte e retrocesso. Nesse contexto, as políticas sociais referentes ao tripé da Seguridade Social passaram a ser estrategicamente intensificadas, devido ao desmonte dos direitos sociais e trabalhistas, como meio de combate às mudanças objetivas e subjetivas advindas da nova organização do mundo do trabalho e de enfrentamento das crises. Portanto, as políticas sociais são transformadas em mercadorias para valorização do capital.

Diante da crise, seja estrutural ou conjuntural, há tendência de aprofundamento da economia capitalista em relação à regulação das relações sociais de produção e reprodução, logo, das políticas sociais. De acordo com Boschetti (2016), a restauração capitalista após a década de 1970, sob a hegemonia neoliberal, provocou a irrupção da crise de 2008, ainda em curso. Assim, as particularidades da crise contemporânea põem sob novas condições as relações entre trabalho, assistência social e seguro na estruturação do Estado social capitalista.

Destarte, acompanha-se a um desmonte da Seguridade Social, com impactos na Proteção Social e regressão de direitos, além da implementação intensa de cortes nos programas de transferência de renda, como o Bolsa Família, e desenvolvimento de novos programas paralelos aos existentes, como o Criança Feliz. Esses processos repercutem em efeitos contraditórios no tocante à melhoria das condições de vida das famílias que se encontram em situação de vulnerabilidade. Tendo isso em vista, "o avanço do capital sobre as políticas sociais é um traço do capitalismo contemporâneo" (MARQUES, 2018, p. 109).

Portanto, ao desenvolver novas estratégias para reestruturar o poder dominante, a sociedade capitalista intensifica a expropriação dos direitos sociais e trabalhistas, configurando um desmonte da Proteção Social. Neste sentido, as políticas sociais perdem dimensões de sua funcionalidade, ocorrendo sua redução, fragmentação e focalização na pobreza e na financeiri- 


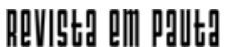

\} A RESPONSABILIZAÇÃO DA FAMÍlIA NA CENA - ARCOVERDE, A. C. B.; ALCANTARA, E. C.; BEZERRA, J. C. \}

DOI: $10.12957 /$ REP.2019.45221

zação. Exige-se, destarte, maior participação de outros atores sociais para responder a funções anteriormente destinadas ao aparelho estatal.

\section{Família e políticas sociais no contexto de crise: proteção ou culpabilização?}

No Governo Dilma Vana Rousseff (2011-2016), se exacerba uma crise de direção política com regressão geral a partir de 2014, fator primordial para o estabelecimento do golpe de 2016. Após a construção de um golpe jurídico-parlamentar, concretizado com o processo de impeachment, é empossado no governo, como chefe do Poder Executivo, o até então vicePresidente Michel Miguel Elias Temer Lulia. A partir deste momento, efetivase de fato e nitidamente o retrocesso dos direitos sociais, que, ressalta-se, já vinham sendo realizados homeopaticamente em governos anteriores. A situação agrava-se ainda mais com a eleição, em 2018, do atual presidente, Jair Messias Bolsonaro, o qual se elegeu com promessas de reformas liberais na economia e um "discurso" ${ }^{3}$ altamente conservador.

O contexto de crise, intensificada com a regressão de direitos sob a Gestão Temer (2016), é caracterizado por processos de restrição de direitos por meio do discurso ideológico de retomada do crescimento econômico; para tanto, acompanha-se o agravamento da desigualdade social ${ }^{4}$. O Estado, no governo de exceção, assume um caráter limitado, e suas políticas regressivas $^{5}$ oneram ainda mais a classe trabalhadora com a perspectiva de redução de gastos, mas ampliando sua função para valorizar o capital.

Verifica-se, neste sentido, que a acumulação do capital será sempre antagônica às necessidades sociais e, diante das crises, identificam-se manifestações próprias desse antagonismo entre produção social e apropriação privada. Diante disso, a funcionalidade do Estado volta-se para o atendimento a demandas capitalistas, havendo a necessidade de reconfigurar o provimento da Proteção Social.

É nesta realidade de intensificação de contradições nas relações sociais capitalistas que a família é ressignificada estrategicamente para contribuir no provimento da Proteção Social. De acordo com Campos e Teixeira (2010, p. 23), esta condição, conhecida como "familista" ${ }^{6}$, presente há muito,

\footnotetext{
${ }_{3}^{3}$ Poucas vezes o atual presidente da República Federativa do Brasil compareceu a espaços públicos e/ou privados para apresentar e debater a sua proposta de governo, restrita à divulgação em redes sociais.

${ }^{4}$ De acordo com estatística do IBGE (2018) e dados do Relatório da Oxfam (2018), em 2017, foi observado, pelo terceiro ano consecutivo, o aumento na proporção da população brasileira que vive na pobreza - aqueles que sobrevivem com renda diária de até US\$1,90, pouco mais de R \$ 7 , de acordo com definição do Banco Mundial. ${ }^{5}$ Observam-se um processo de cortes nas políticas sociais com a aprovação da emenda constituicional $\mathrm{n}$ 95/ 2016, a qual congela por 20 anos os gastos públicos com educação, saúde, assistência social, dentre outros (BRASIL, 2016a).

${ }^{6}$ Identificada como aquela em que há intensa e sistemática responsabilização das unidades familiares pela proteção social de seus membros (CAMPOS, 2008).
} 


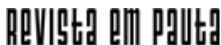

\} A RESPONSABILIZAÇÃO DA FAMÍLIA NA CENA - ARCOVERDE, A. C. B.; ALCANTARA, E. C.; BEZERRA, J. C. \}

DOI: $10.12957 /$ REP.2019.45221

foi ainda mais reforçada a partir de 2000, com o avanço do ideário neoliberal de retração do tamanho e do poder do Estado.

Numa conjuntura do Estado de recorte neoliberal, a desresponsabilização do aparelho estatal avança, fazendo isso por meio da Proteção Social via Programa Criança Feliz, quando a família é convocada a exercer determinadas funções com o intuito de atender às suas próprias necessidades sociais. Dessa maneira, ela é responsabilizada a assumir papéis referentes à reprodução social dos sujeitos, que reiteram as razões do crescimento da desigualdade, desemprego e regressão de direitos.

Considerada célula mater da sociedade ou a base sobre a qual outras atividades de bem-estar se apoiam, a família ganhou relevância atual justamente pelo seu caráter informal, livre de constrangimentos burocráticos e de controle externos [...]. Há preponderantemente, o desenho espontâneo de cuidar e a predisposição para proteger, educar e até para fazer sacrifícios. Isso não poderia parecer mais favorável a um esquema de bem-estar que, como o pluralismo, valoriza e explora a flexibilidade provedora, as relações de boa vontade e o engajamento altruísta. (PEREIRA, 2006, p. 36).

No Governo Pós-Golpe, agravado por uma crise econômica e política, verificam-se a busca e a construção de estratégias articuladas e desenvolvidas pelo capital, que avançam no sentido de responsabilizar ainda mais o Estado para assegurar e modificar as relações entre as classes sociais, em detrimento da classe trabalhadora. $O$ intuito é manter a legitimação da burguesia enquanto classe dominante e garantir a acumulação do capital. Tendo em vista que a economia capitalista regula as relações sociais de produção e reprodução, a família constitui-se num importante sujeito e, ao mesmo tempo, mecanismo para assumir as próprias necessidades sociais, respondendo contraditoriamente a interesses capitalistas.

De acordo com Sposati $(2009$, p. 21), estruturar o sistema da rede de Proteção Social "significa prevenção, o que supõe a redução de fragilidade aos riscos, que podem ser permanentes ou temporários, e que passam a fazer parte do exame da questão do enfrentamento de riscos sociais". Em se tratando da Política Nacional de Assistência Social, observa-se que a Proteção Social é sistematizada enquanto política garantidora da segurança de sobrevivência (de rendimento e autonomia), de acolhida e de convívio ou vivência familiar. Contudo, ao responsabilizar a família, o Programa Criança Feliz vai numa direção oposta.

O conteúdo da assistência social se consolida como um pilar do Sistema de Proteção Social Brasileiro, no âmbito da Seguridade Social, a partir da Resolução no 145, de 15 de outubro de 2004, que aprovou a Política Nacional de Assistência Social (PNAS). Segundo a NOB/Suas:

A proteção social de Assistência Social consiste no conjunto de ações, cuidados, atenções, benefícios e auxílios ofertados pelo SUAS para 


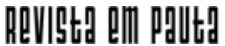

\} A RESPONSABILIZAÇÃO DA FAMÍlIA NA CENA - ARCOVERDE, A. C. B.; ALCANTARA, E. C.; BEZERRA, J. C. \}

DOI: $10.12957 /$ REP.2019.45221

redução e prevenção do impacto das vicissitudes sociais e naturais ao ciclo da vida, à dignidade humana e à família como núcleo básico de sustentação efetiva, biológica e relacional. (BRASIL, 2005, p. 16).

Ainda com relação à Proteção Social, a PNAS (2004) assinala a matricialidade sociofamiliar como eixo central, compreendendo que a família é uma instituição mediadora "das relações entre os sujeitos e a coletividade, delimitando, continuamente os deslocamentos entre o público e o privado, bem como geradora de modalidades comunitárias de vida" (PNAS, 2004 , p. 90). Nesse sentido, os programas e serviços deverão ser direcionados para o atendimento à família, reforçando-a enquanto um dos pilares da rede de Proteção Social.

Vale salientar, ainda, que a família enquanto centro das políticas sociais, com destaque para a política de assistência social, é a protagonista dos serviços e ações. Segundo Teixeira (2016, p. 36): "Não resta dúvida de que o serviço demanda a parceria da família, que prevê divisão de responsabilidades e que a visão de prevenção dos riscos é uma dupla que inclui as funções da família e o papel do Estado".

Diante de tal realidade, é possível afirmar que há um processo de culpabilização e/ou responsabilização das famílias perante o provimento de Proteção Social, visto que se acompanha a uma desproteção social. Esta acontece ao ressaltar as mudanças adotadas na viabilização dos direitos e os cortes implementados pelo Estado para atendimento das necessidades sociais por meio de políticas sociais.

\section{Sobre o Programa Criança Feliz: uma análise da responsabilização da família}

Com a instalação do Golpe, ocorre o desenvolvimento de novos programas sociais em substituição ou detrimento das políticas sociais, como a criação do Programa Criança Feliz, que emerge ainda no Governo Temer. Desde então, a discussão sobre a primeira infância se tornou pauta principal do Governo Federal, através do Ministério da Cidadania ${ }^{7}$ - vinculado à Secretaria Especial do Desenvolvimento Social.

Ressalta-se que essa fase do desenvolvimento humano é marcada por importantes aquisições físicas, cognitivas, emocionais e sociais. Além disso, a primeira etapa da vida humana também é caracterizada pela imaturidade e vulnerabilidade da criança, e por sua condição peculiar de dependência do ambiente e de cuidados de outras pessoas. Neste sentido, a primeira infância é um processo dinâmico e permanente e o desenvolvimento

${ }_{7}^{7}$ Reúne pastas de desenvolvimento social, esportes e cultura, por meio da fusão dos ministérios desenvolvida pelo Governo Bolsonaro em 2019. 


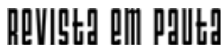

\} A RESPONSABILIZAÇÃO DA FAMÍLIA NA CENA - ARCOVERDE, A. C. B.; ALCANTARA, E. C.; BEZERRA, J. C. \}

DOI: $10.12957 /$ REP.2019.45221

humano está permeado pelas relações sociais, econômicas e culturais, bem como pelo contexto territorial existente.

A valorização crescente dos investimentos na primeira infância, no Brasil, se deu a partir do marco legal da primeira infância, Lei n. 13.257, de 8 de março de 2016, que "dispõe sobre as políticas públicas para primeira infância" (BRASIL, 2016c). Essa lei está em consonância com o Estatuto da Criança e do Adolescente (1990), bem como com a Constituição Federal de 1988, que, no seu art. 227, "implica o dever do Estado de estabelecer políticas, planos, programas e serviços para a primeira infância que atendam às especificidades dessa faixa etária, visando garantir seu desenvolvimento integral" (BRASIL, 1988).

O Programa Criança Feliz, criado em 5 de outubro de 2016 através do decreto $\mathrm{n}^{\circ}$ 8.869, no seu art. $1^{\circ}$ menciona: "Fica instituído o Programa Criança Feliz, de caráter intersetorial, com a finalidade de promover o desenvolvimento integral das crianças na primeira infância, considerando sua família e seu contexto de vida" (BRASIL, 2016b). Destacam-se como objetivos do Programa Criança Feliz:

I - promover o desenvolvimento humano a partir do apoio e do acompanhamento do desenvolvimento infantil integral na primeira infância;

II - apoiar a gestante e a família na preparação para o nascimento e nos cuidados perinatais;

III - colaborar no exercício da parentalidade, fortalecendo os vínculos e o papel das famílias para o desempenho da função de cuidado, proteção e educação de crianças na faixa etária de até seis anos de idade;

IV - mediar o acesso da gestante, das crianças na primeira infância e das suas famílias a políticas e serviços públicos de que necessitem;

$\mathrm{V}$ - integrar, ampliar e fortalecer ações de políticas públicas voltadas para as gestantes, crianças na primeira infância e suas famílias. (BRASIL, 2016, p. 1).

Observa-se que o público-alvo do programa supracitado são: gestantes, crianças de até seis anos e suas famílias, bem como suas particularidades e complexidades, que envolvem toda conjuntura familiar e comunitária. Além disso, alguns dados levantados pelo atual Ministério da Cidadania, entre 2016-2019 ${ }^{8}$, sobre o referido programa são relevantes. Dentre eles destacam-se: o Programa Criança Feliz está presente em 2.622 municípios brasileiros; e entre o público atendido somam-se 604 mil crianças e gestantes.

${ }^{8}$ Dados disponíveis através do site oficial do Ministério da Cidadania. Disponível em: < http://mds.gov.br/assuntos/ crianca-feliz/crianca-feliz/o-crianca-feliz> acesso em: 11.09.2019. 


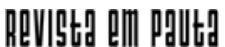

\} A RESPONSABILIZAÇÃO DA FAMÍlIA NA CENA - ARCOVERDE, A. C. B.; ALCANTARA, E. C.; BEZERRA, J. C. \}

DOI: $10.12957 /$ REP.2019.45221

Em relação aos recursos financeiros dispensados aos municípios que realizaram o termo de aceite do programa em 2017, a portaria $\mathrm{n}^{\circ} \mathbf{4 4 2}$, de 26 de outubro de 2017, "dispõe sobre o financiamento federal das ações do Programa Criança Feliz, no âmbito do Sistema Único de Assistência Social, e dá outras providências". Observa-se, ali, que para os municípios garantirem $100 \%$ dos recursos para execução do programa necessitam minimamente realizar, segundo a referida portaria:

I - Uma visita domiciliar por mês para gestantes e suas famílias beneficiárias do Programa Bolsa Família - PBF;

II - Quatro visitas por mês para crianças de 0 a 36 meses e suas famílias beneficiárias do PBF e do Benefício de Prestação Continuada- BPC;

III - duas visitas por mês para crianças de 37 a 72 meses e suas famílias beneficiárias do BPC. (BRASIL, 2017).

Isso significa que terão que recompor seu quadro de recursos humanos consoante os critérios estabelecidos pela portaria supracitada. Apesar disso, para grande maioria dos municípios brasileiros, lidar com o limite prudencial é um grande desafio, uma vez que a contratação dos funcionários públicos que atuam, especificamente, na política de assistência social é realizada através de contratos de trabalho por meio de seleção simplificada e/ou cargos comissionados. Além disso, as famílias passam a, mais uma vez, representar um meio de balizar a vinda de recursos federais aos municípios, sendo incluídas como metas pelas quais são contabilizadas mensalmente, gerando números e ganhos para a gestão pública municipal.

As particularidades referentes à criação, desenvolvimento e sustentação do programa revelam um conjunto de retrocessos para a viabilização de direitos e materialização das políticas sociais. Destacam-se, ainda: o enfoque na intersetorialidade das políticas, ou seja, um único programa capaz de atender a questões referentes à saúde, cultura, justiça, direitos humanos, assistência social e educação; o apoio de parceiros de cunho filantrópico ou voluntário e privado, bem como de organizações internacionais; e a gestão é assumida pela primeira-dama, retornando assim ao primeirodamismo.

Apesar de a Proteção Social ter na família sua matricialidade, de acordo com a nota pública do Conselho Federal de Serviço Social (CFESS), de 7 de março de 2017, o Programa Criança feliz prioriza o "terceiro setor", reforçando a responsabilização da sociedade civil pela execução da política sem garantia de sua direção (Silveira, 2017). Isso vai na contramão da Loas e do Suas, que priorizam a execução direta do Estado nos serviços, programas e projetos.

A desresponsabilização do Estado remete ao período anterior à CF/88 e à Lei Orgânica da Assistência Social (Loas/1993), na qual a assistência 


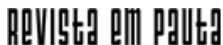

\} A RESPONSABILIZAÇÃO DA FAMÍLIA NA CENA - ARCOVERDE, A. C. B.; ALCANTARA, E. C.; BEZERRA, J. C. \}

DOI: $10.12957 /$ REP.2019.45221

social era operacionalizada via ações de "caridade" realizadas pelas primeiras-damas, a exemplo da Legião Brasileira de Assistência Social (LBA). Esta, no Período Varguista, ficou marcada por ações focalistas, assistencialistas e pela ausência da perspectiva dos direitos sociais.

Não é à toa que a família é o centro de todos os programas, projetos e serviços socioassistenciais. Segundo Teixeira (2016, p. 34), "a forma de incorporação da família na política social vai refletir no direcionamento e na posterior condução do trabalho social com as famílias". Portanto, a matricialidade sociofamiliar, diretriz central da política de assistência social, sugere uma atenção maior voltada para como deve ser a "atuação dos responsáveis pela harmonia do seio familiar". Isso, segundo Teixeira (2016), retorna à família, valorizando-a e potencializando suas funções mais protetivas, retratadas em todas as políticas sociais contemporâneas nas funções clássicas do cuidado, da assistência e da educação. Neste caso, o apelo moral é um forte vetor de responsabilização do sujeito (a família), deixando de lado o vetor sociopolítico, ao mesmo tempo em que se desresponsabiliza o mediador civilizatório (Estado) da sua função de assegurar Proteção Social.

Não é diferente das concepções apresentadas pelo programa. Salienta-se que, na metodologia abordada, bem como nas orientações técnicas voltadas para os chamados "visitadores sociais", existem até direcionamentos sobre como "educar a mãe a amamentar seu filho", dentre outros destaques dessa natureza. Tais características corroboram com a responsabilização da família diante de sua situação de vulnerabilidade social, afinal, o programa tem o intuito de desenvolver potencialidades do sujeito e estimular a responsabilidade dos adultos para assumir tarefas que não são unicamente suas.

A família, base fundamental da sociedade, trazida pela CF/88 em seu art. 226, que possui "especial proteção do Estado", atualmente é incumbida do dever de se "autoproteger" das vulnerabilidades sociais (BRASIL, 1988). Ademais, a ela mesma cabe o papel da defesa e do desenvolvimento de sua função protetiva, ou seja, cabem aos "pais desempenharem adequadamente seu papel na socialização, no cuidado, na assistência, no provimento e na proteção dos filhos" (TEIXEIRA, 2016, p. 35).

Comprova-se, então, a busca de transferências de funções estatais de responsabilidade com o social para setores da própria sociedade, principalmente objetivando desresponsabilizar o Estado perante o desenvolvimento de políticas de cariz público. O Estado, então, vai se constituindo como fiel depositário de interesses privados em detrimento dos coletivos, em que a cultura do favor, clientelismo e patrimonialismo alicerçam a via de acesso aos direitos sociais no Brasil. Assim é moldado o perfil das políticas sociais, irrompendo no trabalho profissional com famílias (DUARTE, 2018).

Neste intuito, a cartilha do programa traz que "[...] a intersetorialidade ocupa lugar central na operacionalização e efetivação do Programa Criança Feliz [...]", e reforça que: 


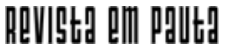

\} A RESPONSABILIZAÇÃO DA FAMÍlIA NA CENA - ARCOVERDE, A. C. B.; ALCANTARA, E. C.; BEZERRA, J. C. \}

DOI: $10.12957 /$ REP.2019.45221

A capacidade de compreender e encaminhar tais demandas, e uma postura transparente em caso de impossibilidade são peças centrais para a efetivação das visitas como método para o fortalecimento da capacidade protetiva das famílias e do diálogo com o programa. (BRASIL, 2017, p. 23).

Além de todos os pontos mencionados, há alguns questionamentos sobre o referido programa ainda sem respostas convincentes: por que não direcionar os recursos desse programa para os serviços tipificados já existentes na política de assistência social, como por exemplo o Serviço de Convivência e Fortalecimento de Vínculos (SCFV)? Ou para o Serviço de Proteção e Atendimento Integral à Família (Paif)? Essas são indagações que os militantes do Sistema Único da Assistência Social discutem. Apesar disso, mais de $80 \%$ dos municípios do país aderiram ao programa por receio de perder recurso para assistência social, uma vez que os orçamentos são menores a cada ano, seguindo a emenda constitucional n 95/2016, que congela por vinte anos investimentos nas políticas sociais (BRASIL, 2016a). A nosso ver, é uma contradição estrutural na política, na relação Estado $x$ sociedade e nas suas responsabilidades públicas.

Ainda no que diz respeito ao Programa Criança Feliz, sabe-se que, diferentemente da política de assistência social, que congrega as demandas presentes na sociedade, pautada em serviços que visam ao usuário como sujeito de direitos, o programa sinaliza uma possível ruptura dos ganhos e direitos. Esses foram garantidos com tanta luta e esforço da sociedade brasileira no decorrer desses 30 anos, desde a efetivação da CF/ 88, até a constituição do Suas em 2004, através da PNAS.

Portanto, as particularidades referentes aos objetivos a que se destina o programa analisado contribuem para identificar uma desresponsabilização estatal diante da prevalência do atendimento às necessidades dos sujeitos por meio do voluntariado e terceiro setor. Mas também, e principalmente, pelo enfoque na responsabilização da família no cuidado, na proteção e na educação, pois, como o Estado já não é o principal responsável pela Proteção Social, o princípio liberal da autossustentação recai com força sobre as famílias, desprotegendo-as.

\section{Notas conclusivas}

O Programa Criança Feliz e suas particularidades vão na contramão dos direitos e da assistência social como um direito, promovendo um sucateamento dos mesmos. Isso acontece uma vez que o conteúdo do programa e sua operacionalidade constituem-se em mais um passo para a construção de um viés ideológico e político que restringem e eliminam direitos. Contribui, dessa maneira, para uma possível fragilização das políticas 


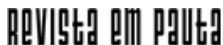

\} A RESPONSABILIZAÇÃO DA FAMÍLIA NA CENA - ARCOVERDE, A. C. B.; ALCANTARA, E. C.; BEZERRA, J. C. \}

DOI: $10.12957 /$ REP.2019.45221

sociais, ora identificadas como "universais", fortalecendo perspectivas conservadoras.

Compreender a dinâmica das políticas sociais na ordem capitalista ainda é desafiador, principalmente quando exploramos sua constituição histórica e elementos trazidos pelo modo de produção capitalista em meio à sociedade. O capitalismo desenvolve constantemente estratégias com o intuito de enfrentar e/ou superar os momentos de crises, sem alterar sua estrutura de acumulação. Assim, necessita expropriar cada vez mais as garantias estabelecidas, responsabilizando os sujeitos e destituindo-os dos direitos sociais sob um protagonismo alienado.

A responsabilização da família frente às expressões da questão social, como no caso do Programa Criança Feliz - resposta pública às situações de vulnerabilidade social -, é a vertente observada no cerne das políticas sociais, em destaque nas ações dos programas, projetos e serviços socioassistenciais. Esses podem, sob efeito moralizador, resultar na culpabilização e penalização das famílias pela responsabilidade de resolver seus próprios problemas e atender às suas necessidades, que são de fato questões inerentes ao próprio sistema capitalista e ao modo como a regulação acontece. Convergimos com Duarte (2018) quando expõe que é preciso reconhecer a centralidade do trabalho explorado e da questão social como inerentes à relação capital x trabalho, e não da família.

O Programa Criança Feliz é um exemplo de como a gestão do Governo Temer (2016) buscou uma estratégia conservadora de retorno ao assistencialismo com o primeiro-damismo, nos novos marcos legais de consideração da primeira infância. Tanto o Programa Criança Feliz, como os marcos legais orientadores dificultam o entendimento e a resposta dos profissionais da assistência social, que vêm tentando superar essa visão e/ou perspectiva desenvolvendo suas práticas na direção do acesso e usufruto dos direitos sociais.

Assim, embora o Programa Criança Feliz tenha disponibilizado para os municípios um maior percentual de recursos (que foram realocados de outros serviços da assistência social) para a execução da Proteção Social Básica, responsável pela prevenção e "manutenção" dos vínculos familiares, expressa piamente a contradição entre as atribuições da política de assistência social e o seu sistema de Proteção Social. Tem-se a família ora como sujeito que necessita do acesso aos direitos, ora como alvo da responsabilização e culpabilização do seu estado de vulnerabilidade e risco social.

A intersetorialidade na articulação com as políticas de saúde, educação e assistência social, fundamental ao atendimento com qualidade das múltiplas expressões da questão, termina sendo atribuída a um único programa, que de fato não possui potencial. Portanto, a intersetorialidade do Programa Criança Feliz fica apenas no discurso vazio, porquanto tornase, na gênese, inviabilizado. 


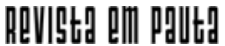

\} A RESPONSABILIZAÇÃO DA FAMÍLIA NA CENA - ARCOVERDE, A. C. B.; ALCANTARA, E. C.; BEZERRA, J. C. \}

DOI: $10.12957 /$ REP.2019.45221

Por fim, é notório que mais uma vez se desrespeita o marco legal construído em 1988 com a Constituição Federal, cuja implementação e impactos sociais são esperados pela tipificação nacional dos serviços socioassistenciais de 2009 em um único programa, desprovido de fundamentos coerentes. Programas como o Criança Feliz não avançam no acesso e garantia dos direitos e terminam se construindo no "faz-de-conta" ou na velha prática política de destruir o construído para construir o marketing do gestor da vez, usando a política social como moeda de troca e ainda responsabilizando a família. 


\section{ReVIStg a p p putto}

\} A RESPONSABILIZAÇÃO DA FAMÍLIA NA CENA - ARCOVERDE, A. C. B.; ALCANTARA, E. C.; BEZERRA, J. C. \} DOI: $10.12957 /$ REP.2019.45221

\section{Referências}

BOSCHETTI, I. Assistência Social e trabalho no capitalismo. São Paulo: Cortez, 2016.

BRASIL. Constituição da República Federativa do Brasil. Diário Oficial da União, 1988.

BRASIL. Política Nacional de Assistência Social - PNAS. Diário Oficial da União, Brasília, 2004.

BRASIL. Norma Operacional Básica - NOB/Suas. Diário Oficial da União, Brasília, 2005.

BRASIL. Constituição da República Federativa do Brasil. Emenda Constitucional no 95, de 15 de dezembro de 2016. Altera o Ato das Disposições Constitucionais Transitórias, para instituir o Novo Regime Fiscal, e dá outras providências. Diário Oficial da União: seção 1, 16 dez. 2016 a.

BRASIL. Decreto no 8.869, de 5 de outubro de 2016. Institui o Programa criança Feliz. Diário Oficial da União, Brasília, 2016b.

BRASIL. Lei $n^{\circ} 13.257$, de 8 de março de 2016. Dispõe sobre as políticas públicas para a primeira infância. Diário Oficial da União, Brasília, 2016c.

BRASIL. Ministério de Desenvolvimento Social. Portaria no 442, de 26 de outubro de 2017. Dispõe sobre o financiamento federal das ações do Programa Criança Feliz, no âmbito do Sistema Único de Assistência Social, e dá outras providências. Diário Oficial da União, Brasília, DF, 26 out. 2017.

CAMPOS, M. S. Família e proteção social: alcances e limites. In: ZOLA, M. B. (org.). Cooperação internacional para proteção de crianças e adolescentes: o direito à convivência familiar e comunitária. São Bernardo do Campo: Fundação Criança de São Bernardo do Campo, 2008.

CAMPOS, M. S.; TEIXEIRA, S. M. Gênero, família e proteção social: as desigualdades fomentadas pela política social. Revista Katalysis, Florianópolis, v. 13, n. 1, jan./jun. 2010.

DUARTE, J. M. G. F. Trabalho social com famílias no Serviço Social: determinações sócio-históricas na reconfiguração das políticas sociais contemporâneas. In: RAICHELIS, R.; VICENTE, D.; ALBUQUERQUE, V. (org.). A nova morfologia do trabalho no serviço social. São Paulo: Cortez, 2018.

HORST, C. H. M.; MIOTO, R. C. T. Serviço Social e o trabalho com famílias: renovação ou conservadorismo? Em Pauta, Rio de Janeiro, n. 40, 2017.

IBGE. Indicadores apontam aumento da pobreza entre 2016 e 2017. 2018. Disponível em: https://agenciadenoticias.ibge.gov.br/agencia-noticias/2012agencia-de-noticias/noticias/23299-pobreza-aumenta-e-atinge-54-8milhoes-de-pessoas-em-2017. Acesso em: 5 jun. 2019. 


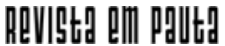

\} A RESPONSABILIZAÇÃO DA FAMÍLIA NA CENA - ARCOVERDE, A. C. B.; ALCANTARA, E. C.; BEZERRA, J. C. \}

DOI: $10.12957 /$ REP.2019.45221

MANDEL, E. A crise do capital: os fatos e sua interpretação marxista. São Paulo: Ed. Ensaios, 1990.

MARQUES, R. M. O capitalismo financeiro e as políticas sociais: a nova face da contemporaneidade. In: RAICHELIS, R.; VICENTE, D.; ALBUQUERQUE, V. (org.). A nova morfologia do trabalho no serviço social. São Paulo: Cortez, 2018.

MÉSZÁROS, I. Para além do capital: rumo a uma teoria de transição. São Paulo: Boitempo Editorial, 2002.

MOTA, A. E. Cultura da crise e seguridade social. São Paulo: Cortez, 2015.

NETTO, J. P. Crise do capital e consequências societárias. Revista Serviço Social e Sociedade, São Paulo, n. 111, jul./set. 2012.

OXFAM. País estagnado: um retrato das desigualdades brasileiras 2018. 2018. Disponível em: https://www.oxfam.org.br/paisestagnado. Acesso em: 1 jun. 2019.

PEREIRA, A. A. P. Mudanças estruturais, política social e papel da família: crítica ao pluralismo de bem-estar. In: SALES, M. A.; MATOS, M. C. de; LEAL, M. C. (org.). Política social, família e juventude: uma questão de direitos. São Paulo: Cortez, 2006.

SILVEIRA, Jucimeri Isolda. Assistência social em risco: conservadorismo e luta social por direitos. Serv. SOC. SOC, n. 130, p. 487-506, 2017.

SPOSATI, A. et al. Assistência na trajetória das políticas sociais brasileiras. São Paulo: Cortez, 2009.

TEIXEIRA, M. S. Sistemas de proteção social contemporâneos e a política de assistência social: a reatualização do familismo. In: TEIXEIRA, M. S (org.). Política de assistência social e temas correlatos. Campinas: Papel Social, 2016.

DOI: $10.12957 /$ rep.2019.45221

Recebido em 30 de junho de 2018.

Aprovado para publicação em 09 de abril de 2019.

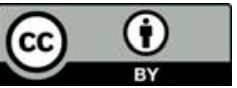

A Revista Em Pauta: Teoria Social e Realidade Contemporânea está licenciada com uma Licença Creative Commons Atribuição 4.0 Internacional. 